\title{
The Impact of Self-Efficacy and Depression on Self-Care in Patients with Heart Failure: An Integrative Review
}

\author{
Harshida Patel ${ }^{1 *}$ and Sumana Ghosh ${ }^{2}$ \\ ${ }^{1}$ Sahlgrenska Academy, Institute of Health and Care Sciences, University of Gothenburg, Sweden \\ ${ }^{2}$ STTI Tau Omega Chapter, University of Gothenburg, Sweden
}

*Corresponding author: Harshida Patel, PhD, MSc, RN, Senior Lecturer, Sahlgrenska Academy, Institute of Health and Care Sciences, University of Gothenburg, P.O. Box 457, 405 30, Sweden, Tel: +4631-786-6047; +46(0)766-18-6047, E-mail: Harshida.patel@gu.se

\begin{abstract}
Background: Although the importance of self-efficacy and depression are mapped out in previous research; there is a lack of clarity about associations between self-efficacy and depression to self-care, and potential implications for nursing care. The purpose of this review was to identify the association between self-efficacy and depression and how it affects self-care in the HF population.

Methods: The study was carried out by conducting a library search in the CINAHL, PubMed, PsycINFO and Cochrane databases from January 2000 - May 2017 yielded 24 studies.

Results: The analysis of these articles showed that several studies documented an inverse association between self-efficacy and depression in the context of self-care. Experimental studies also showed that interventions aimed at increasing self-efficacy and treating depression could encourage self-care practices.

Conclusions: The results suggest that a more holistic view of self-care recommendations that incorporates self-efficacy and depression is of potential value in the future treatment of HF patients.
\end{abstract}

\section{Keywords}

Self-efficacy, Depression, Heart failure, Self-care, Review

\section{Introduction}

Heart Failure (HF) is a complex clinical syndrome resulting from an abnormality of cardiac structure and function [1]. Despite significant advances in the treatment and management of cardiovascular diseases, $\mathrm{HF}$ continues to be a major concern, not only from a medical perspective but also in economic and social terms
[2]. There are 6.5 million patients living with $\mathrm{HF}$ in Europe $[3,4]$ and 5.1 million in the USA [5]. The most recent European data (ESC-HF pilot study) demonstrate that 12-month all-cause mortality rates for hospitalized and stable/ambulatory $\mathrm{HF}$ patients were $17 \%$ and $7 \%$, respectively, and the 12-month hospitalization rates were $44 \%$ and $32 \%$, respectively [6]. Encouraging selfcare and self-efficacy [7-13] and treating depression $[7,12,14,15]$ have all identified as key factors for lowering mortality rates.

Patients with $\mathrm{HF}$ are more prone to depression, with a reported prevalence between $9 \%$ and 60\% [16-18], compared with $5 \%$ to $10 \%$ in the normal population in Europe [19]. The World Health Organization defines depression as a common mental disorder, characterized by sadness, loss of interest or pleasure, feelings of guilt, low self-worth, disturbed sleep and appetite, tiredness, and poor concentration [20]. Recent results from the OPERA-HF study [21] show that moderate to severe depression is associated with a 5 -fold increased risk of allcause mortality in patients with HF. Patients who were not depressed had an $80 \%$ lower mortality risk [21].

Self-efficacy has been associated with adverse outcomes and has been considered a reasonable proxy for predicting HF hospitalization [22]. Lower baseline self-efficacy is associated with worse cardiac function and increased risk for HF hospitalization. The concept of self-efficacy is based on Bandura's social cognitive theory [13]. The self-efficacy theory of depression focuses on

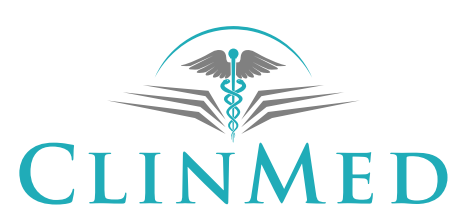

INTERNATIONAL LIBRARY

Citation: Patel H, Ghosh S (2017) The Impact of Self-Efficacy and Depression on Self-Care in Patients with Heart Failure: An Integrative Review. Int Arch Nurs Health Care 3:087. doi.org/10.23937/24695823/1510087

Received: September 22, 2017: Accepted: December 11, 2017: Published: December 13, 2017

Copyright: (C) 2017 Patel $\mathrm{H}$, et al. This is an open-access article distributed under the terms of the Creative Commons Attribution License, which permits unrestricted use, distribution, and reproduction in any medium, provided the original author and source are credited. 
the relationship between cognition of self-devaluation and coping inability and the initiation and persistence of coping behaviors in the face of obstacles [23]. Self-efficacy is related to people's beliefs in their ability to achieve desirable outcomes [13]. Unless people believe that their actions can produce desired effects, they have little incentive to undertake activities or to persevere in the face of difficulties [24]. Locke, et al. have described how people with high self-efficacy choose to perform more challenging tasks, establish higher goals and adhere to them [25]. When setbacks occur, those with high self-efficacy recover more quickly and maintain a commitment to their goals [26]. Self-efficacy is increasingly used in health research as a predictor for improving clinical outcome [27].

Clinical outcomes also depend on the ability of HF patients to manage their self-care. Self-care is a decision-making process that involves the choice of behaviors that include self-care maintenance, management and confidence [28]. In patients with HF, self-care seeks to empower individuals to cope with their disease and to improve their quality of life with fewer restrictions from their illness $[11,29]$. Poor self-care can be a consequence of depression $[12,14,15,30]$, whereas self-efficacy $[7-12,27]$ has a positive effect on self-care. Self-efficacy has also been identified as the mediator between left ventricular ejection fraction and depression in patients with HF $[7,14,31]$. Although the importance of self-efficacy and depression are mapped out in previous research; there is a lack of clarity about associations between self-efficacy and depression to self-care, and potential implications for nursing care. Therefore, the purpose of this review was to identify the association between self-efficacy and depression and how it affects self-care in the HF population.

\section{Methods}

\section{Design}

A tool inspired by Torraco [32] and Whittemore [33] was used to facilitate a systemic appraisal of studies to capture the association between self-efficacy and depression and its effects on self-care in patients with HF.
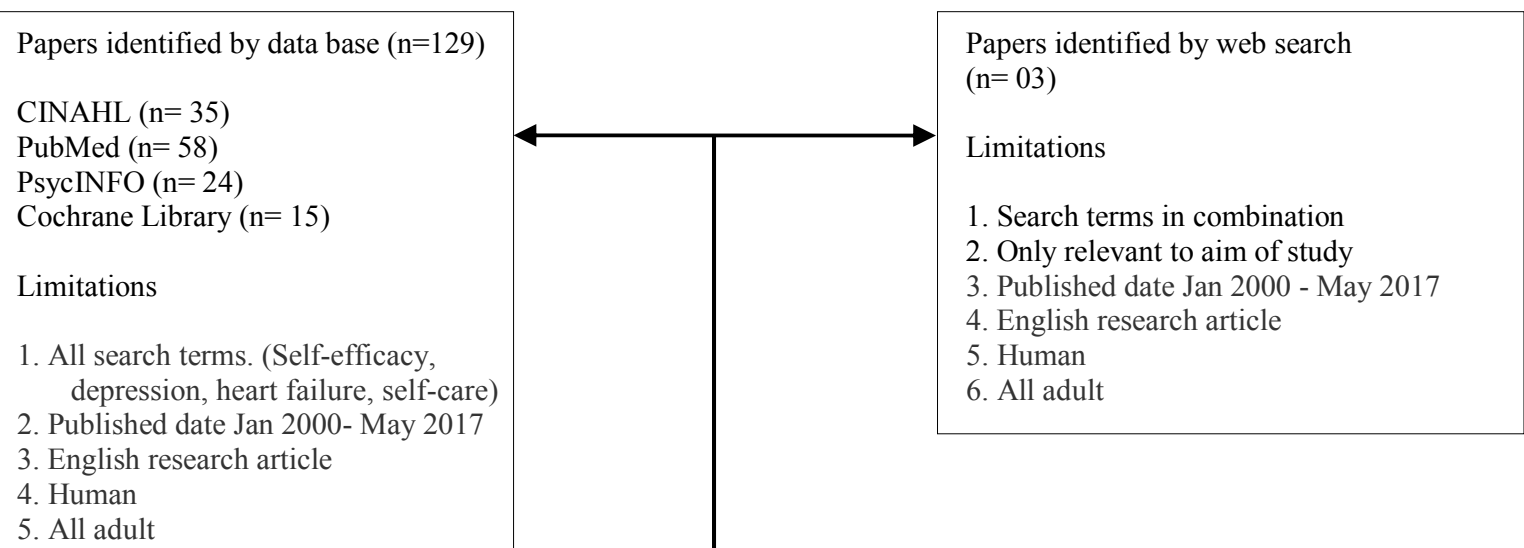

Papers selected and screened by title and abstract for inclusion $(n=89)$

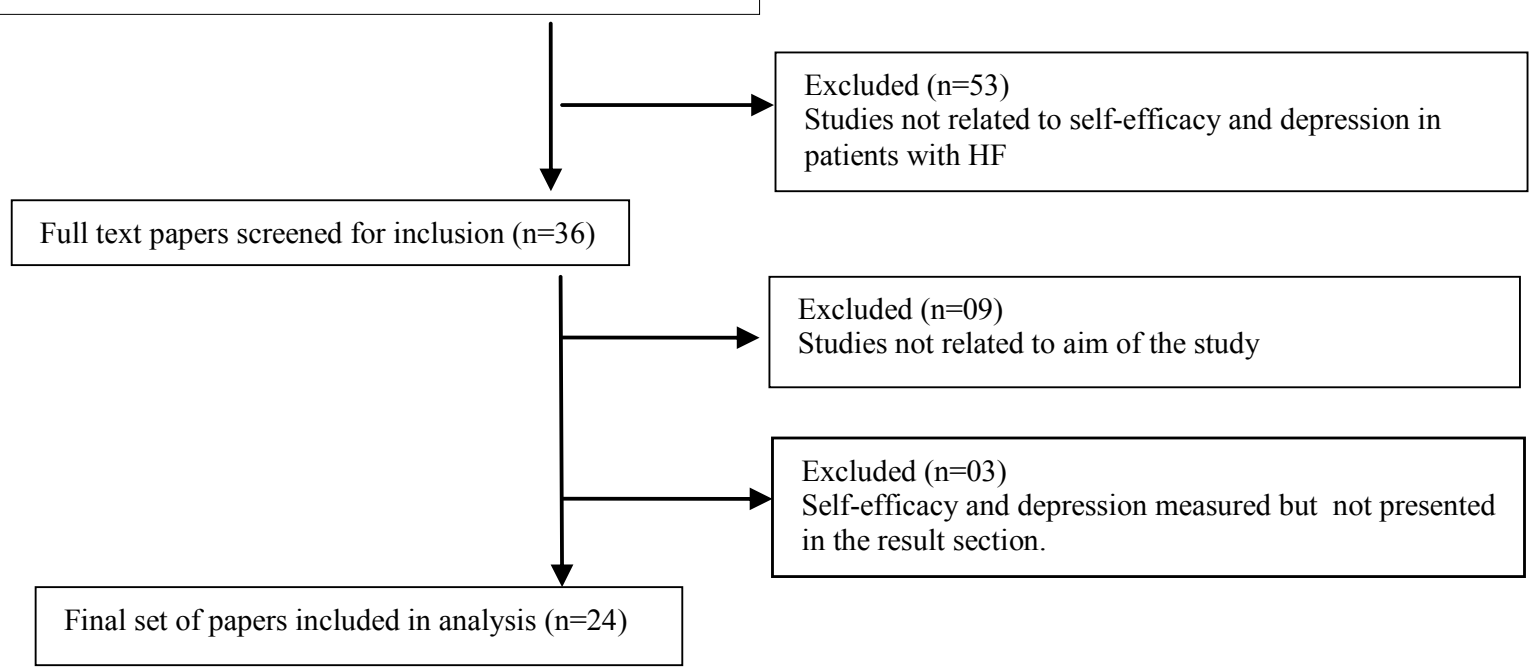

Figure 1: PRISMA flow chart. 
Integrative reviews allow integration of all types of studies (qualitative, quantitative, including Interventional) related to the aim of the study.

\section{Ethical approval}

No formal ethical approval was sought for the study.

\section{Literature search}

Literature was searched in CINAHL, PubMed, PsycINFO and Cochrane library using the following search terms: 'self-efficacy', 'depression', "self-care", and "heart failure' with Boolean operators "AND" and "OR" in different combinations. Research papers reporting qualitative or/and quantitative research, published in English between January 2000 to May 2017 with a focus on self-efficacy and depression in patients with HF and self-care were included in the review. The initial search generated 129 titles and 3 studies of relevance from a web search, which were also found in the PubMed database; CINAHL 35, PubMed 58, PsycINFO 24 and Cochrane library 15 . After exclusion of 43 duplicates, the title and abstracts of 89 studies were retrieved and read. Papers which were not relevant to self-efficacy and depression ( $n=53$ ), with unclear aims of the study $(n=9)$ and those $(n=3)$ which measured self-efficacy or depression but was not presented in the result section were excluded. Finally 24 articles reporting 22 quantitative and two mixed method studies were selected and included in the current review. The data abstraction process is illustrated in (Figure 1). All research articles were screened for eligibility by two reviewers (HP and SG), and if inclusion criteria were met, they underwent a dual review for data abstraction. Confirmability was measured by external checks ("peer-debriefing") conducted by colleagues who were familiar with review research.

\section{Quality appraisal}

Evaluation of the quality of the sources in an integrative review is complex [33]. The quality assessment criteria used were inspired by Torraco [32] and Whittemore [33]. The areas addressed in the studies to ensure methodological quality, informational value and representativeness are described in the Table 1. Fulfilment of each criterion was given a score of 1 point. All studies went

Table 1: The quality assessment criteria, inspired by Torraco [32] and Whittemore [33].

1) Is paper published in peer reviewed journal?

2) The research aims/questions/objectives/hypothesis are clear and appropriate

3) Sample size/number of participants are given

4) Sampling/recruitment/randomization are adequately described

5) Clear overview of intervention (if applicable) is given to use of appropriate outcome measures

6) Data analysis is adequately described and rigorous

7) Ethical issues are suitably addressed through this criterion and had total scores of 5 - 7 points. Both authors (HP and SG) assessed the quality of all the included studies independently, with $92 \%$ agreement rate; disagreements were discussed and then reconciled.

\section{Data extraction}

The data from 24 studies were abstracted and analysed. The first author performed data extraction using a data table and the second author reviewed the data table for accuracy. Abstracted data elements included first author, year, country, study purpose, study design, sample size, population, settings, measures used, conceptual framework and major findings/outcome (Table 2). The studies were conducted in 9 different countries and represented multiple disciplines: Nursing, medicine, psychology, psychiatry and behavioural sciences, clinical epidemiology and Biostatistics, medical Biometry and informatics, social and behavioural sciences, social welfare and social work.

\section{Results}

\section{Sample sites and countries}

Included studies were conducted in the USA [34-49], Australia [50], Canada [51], China [52], Germany [53], Netherland [54], New Zealand [55], Poland [56], and Taiwan [57]. The majority of the studies were single site studies, however, one study included participants from 13 centers [49] and another one from 3 centers [55].

\section{Population and sample sizes}

There were mainly two categories of the population studied in the reviewed articles: Patients with HF [34$37,40-43,46-53,56,57]$ and patients with $\mathrm{HF}$ and other conditions $[38,39,44,45,54,55]$. Three studies in the review specified the type of HF which included systolic HF $[47,53,56]$, and diastolic HF [37]. The study participants in each study sample were recruited from hospitals, out-patient clinics, primary care centers, home settings, and rehabilitation centers. Adult male and female participants were identified from medical records.

Sample sizes for the included studies ranged from 16 to 522 [34-57]. Nine studies [35-40,47,48,55] used random sampling methods, especially block randomization [47]. Randomization was not reported in the remaining studies $[35-40,48,55]$. Two studies used convenience sample $[44,51]$ and 13 studies $[34,41-43,45,46,49,50,52-$ $54,56,57]$ did not mention sampling technique.

\section{Research design and measurement tool}

Among the reviewed studies, ten [41-44,46,49-53] were cross-sectional, eight $[35-40,47,48]$ were Randomized Controlled Trials (RCTs), one [54] used repeated measure design, and another used correlational design [57]. The remaining studies were prospective comparative $[45,56]$, mixed method $[34,55]$. The two major concepts, self-efficacy and depression, were measured in all the studies in the context of self-care in patients with HF. 


\section{Data analysis}

Each individual paper was read and the pieces of information related to the aim and thoughts on what and how to write the review were noted with references. This resulted in a first rough draft of the review [32]. In the next step, data was classified based on the topic, e.g. the identification of main concepts studied individually $[40,43,45]$, associations with self-care $[35,36,38,39,44,46,50-55]$, and relationship between self-efficacy and depression [34,37,41,42,47-49,56,57]. Next, the data was extracted and compiled into a spreadsheet to enable systematical comparison on selfcare issues in relation to depression and self-efficacy. After that the data were displayed in the table as shown in Table 2, to enhance the visualization of patterns and association within and across the included papers. Data inserted in the table served as a starting point for interpretation. Commonalities and differences were identified to describe the associations between self-efficacy and depression in the context of self-care.

The review of the research showed that both perceived self-efficacy and depression were somehow associated to self-care. Overall, this integrative review supported the proposed two major themes of association between self-efficacy and depression in patients with HF: General self-efficacy and depression $[35,38,40,42,48,52,54-57]$, and specific self-efficacy and depression [34,36,37,39,41,43-47,49-51,53] (Figure 2). General self-efficacy is the belief in one's competence to attempt a difficult or novel task and to cope with adversity arising from a particular demanding situation, whereas specific self-efficacy refers to the beliefs about one's ability to perform a specific task such as medication, exercise or diet self-care behavior [58].

\section{General self-efficacy and depression}

General self-efficacy and depression was explored in 10 studies [35,38,40,42,48,52,54-57]. Six studies $[38,42,52,54,56,57]$ identified an inverse relationship, and assert that individuals with high levels of perceived self-efficacy manage their HF better, which in turn leads to a reduction in depression. On the contrary, two studies $[35,40]$ used different interventions, such as educational support delivered in the home by nurses [35] and telehealth communication [40]. Both studies showed improved general self-efficacy with interventions, but did not find any differences in depression between groups. One study [38] described integrated telehealth interventions combined with chronic illness and depression care, with a telehealth nurse conducting daily tele-monitoring of each patient's condition as well as weekly sessions of problem-solving treatment for depression. Findings showed significant improvement in self-efficacy in managing their medical condition and lowered depression scores. In contrast, two studies $[48,55]$ found that interventions aimed to decrease depression did not affect self-efficacy but patients in Telecare group reported feelings of safe and improved self-care [55]. Another study from Taiwan [52] found general self-efficacy and depression to be independent factors with negative correlation for managing self-care in HF patients.

\section{Specific self-efficacy and depression}

The focus of inquiry of 14 studies [34,36,37,39,41,4347,49-51,53] was specific self-efficacy, where four types of specific self-efficacy were identified: Medication adherence, dietary, physical activity/exercise and sexual behavior. The studies showed a direct or indirect association between self-efficacy and depression $[34,36,37,39,41,45,47,49]$, no association $[44,46,50,51,53]$, and self-efficacy as a mediator $[44,46,53]$ or as an independent predictor of the self-care $[34,41,43,49,50]$.

Although self-efficacy and depression were common concepts in the reviewed studies, there was inconsistency in the findings. Only six $[34,36,37,41,47,49]$ studies were in consensus that higher self-efficacy and lower depression promoted self-care, rest of the studies presented diverse results. For example, self-efficacy was

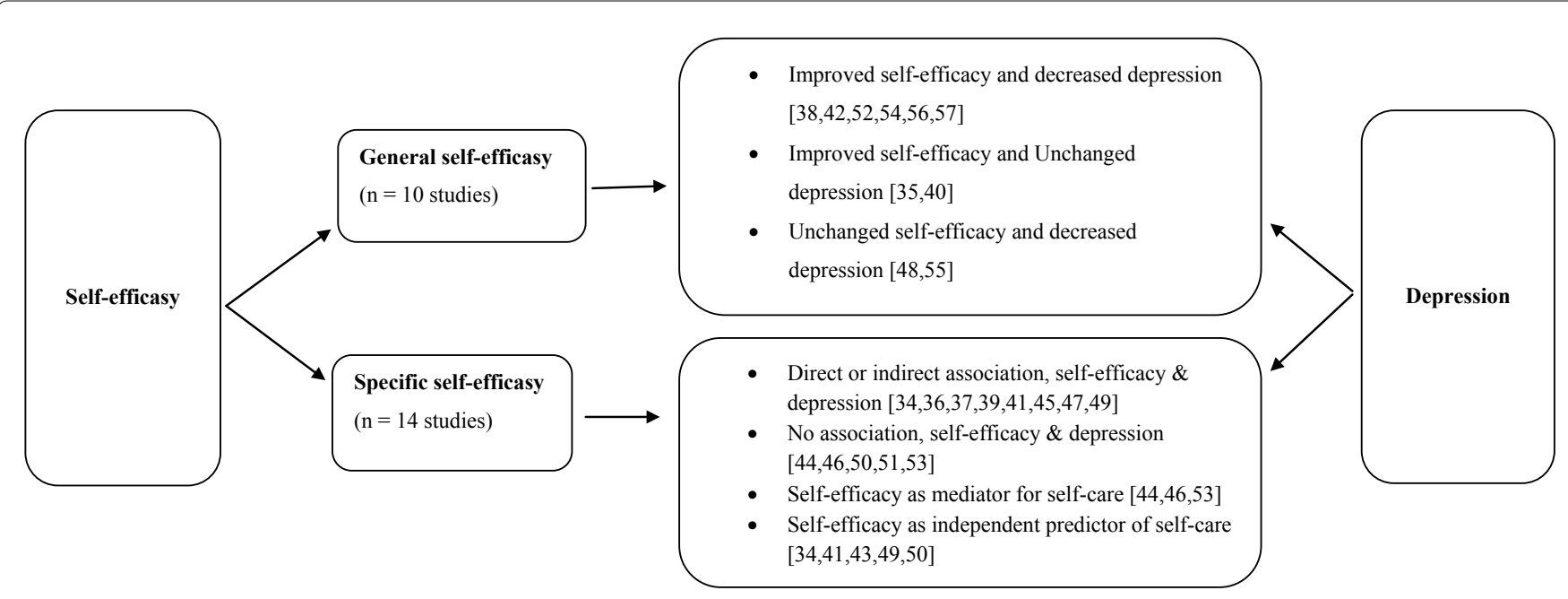

Figure 2: Illustration of self-efficacy and depression to self-care in the reviewed studies. 
described as a mediator for self-care [46]. Rosland [44] found a negative impact on self-efficacy and depression when family members took over the responsibility of self-care from the HF patient. Jerant, et al. [39] investigated the moderating effect of depressive symptoms to enhance patient self-efficacy for self-care and found that individuals with more depressive symptoms seem more likely to experience self-efficacy gains from selfcare enhancing interventions.

Medication adherence: Self-efficacy and depression influenced self-care in terms of medication adherence. In general, patients with higher self-efficacy and lower depression had higher medication adherence $[34,41,49]$. On the contrary, patients with difficulty taking medications had less self-efficacy and more depressive symptoms [34]. On the other hand, Schweitzer and colleagues [50] found that self-efficacy was a better predictor for medication adherence than depression, whereas Maeda, et al. [41] found that self-efficacy explained the influence of depression on medication adherence.

Dietary: One study from Australia [50] presented results about dietary self-efficacy in relation to depression, showing that depression failed but self-efficacy predicted behavioral variability in salt restriction adherence behavior.

Physical activity and exercise: The studies about self-care related to physical activity/exercise in the current review found overall positive effects on self-efficacy and depression with different interventions. Three studies $[36,37,47]$ found that exercise training decreases depression and increases exercise self-efficacy. In contrast, Reschke [43] found that depression, and self-efficacy were independent predictors of walk test performance. The author concludes that depression explains HF patients' poor performance in spite of good aerobic capacity. Yeh, et al. [47] included only men and showed improved scores on depression with tai chi compared to aerobic exercise, though both groups had improved self-efficacy, whereas Gary, et al. [37] included only women and found that women in a walking programme improved their self-efficacy and decreased depressive symptoms. Further study findings indicated that depression in women with $\mathrm{HF}$ is common and may go unrecognized and undertreated with consequences on self-efficacy and self-care.

Sexual behaviour: The literature search yielded only one study on sexual self-efficacy and depression [45]. The authors of this study found that the participants who were not sexually active had lower sexual self-efficacy and sexual satisfaction. There was no difference in sexual depression scores between sexually active and sexually not active participants [45], but patients with HF had higher scores on overall depression scores than healthy elders.

\section{Discussion}

We reviewed the association between self-efficacy and depression and how it affects self-care in HF patients. Our initial idea was to only investigate the association between self-efficacy and depression in $\mathrm{HF}$ patients, but we failed to find studies describing self-efficacy and its association with depression without context. Hence, we decided to include studies addressing the association between self-efficacy and depression in self-care contexts.

The review showed that self-efficacy and depression were important variables influencing self-care, by shaping how individuals prioritized and integrated multiple and often competing self-care instructions. In several studies, high self-efficacy was shown to promote acceptance of limitations and capitalization of strengths, which in turn was found to encourage continued efforts of self-care. Thus, patients with high self-efficacy were shown to be more likely to stay engaged even when confronted by obstacles. On the contrary, low self-efficacy and obstacles like inadequate heart failure knowledge has been associated with poor heart failure selfcare $[59,60]$.

However, this was not the case in all the studies, as some studies found self-efficacy and depression as independent variable with influence on the self-care $[34,48,55]$. Interestingly, the identified discrepancy coincides with a variation in research method, namely between qualitative and quantitative findings [55], contributing to the deviant results. It is possible that subjective aspect of self-efficacy was under-detected. Another explanation may be that a follow-up of 12-weeks was too short to measure changes in self-efficacy, or that both groups were treated with antidepressants $[48,55]$.

Furthermore, the results from few studies also suggested self-efficacy as a mediator for depression in self-care adherence; but the cross sectional design [4144,46,49-53] and the fact that these studies mostly included younger HF $[44,46,53]$ makes it difficult to make appropriate inference. Especially in case of chronic diseases like HF, the results from cross-sectional studies cannot show if self-care, for example medication adherence, affects self-efficacy and depression in a limited chosen time frame. Patients might have poor adherence temporarily because of experienced side effects of the medication, other co-morbidities or emotional factors might influence self-efficacy and/or depression at the time of measurement. Besides, common symptoms of $\mathrm{HF}$, like fatigue, might overlap depression and may easily be misinterpreted.

Previous research has found that a sense of self-efficacy can be a mediator to chronic illness deterioration and the occurrence of depressive symptoms [61], which may affect self-care. One of the studies [56] in the current review described patients with $\mathrm{HF}$ as having the 
highest sense of self-efficacy compared to patients with diabetes, post-myocardial infarction and women after mastectomy. These results should be questioned, however, as this study lacked information about the recruiting process, and only patients with military background were included; these individuals may have a different sense of self-efficacy concept compared to HF patients in general. The sense of self-efficacy and depression may also vary among hospitalized and outpatient individuals with HF. Moreover, self-reported questionnaires assessing psychological measures may be biased as there is a potential risk that responses are reluctant or that they tend to be socially acceptable.

The interventional studies included in the review reported contradictory findings. These may depend on the nurse's expertise, the way education was delivered, and patients' receptiveness. In studies reporting improvement in both groups results may be explained by: 1) High baseline scores in the intervention group [34]; 2) The effect of nurses' support experienced by individuals in both groups [55]; 3) Samples not reflecting the same age-groups as the HF population [46]; 4) Bias of the interventions, as the same nurse conducting interventions also collected data [35]; 5) Low completion rate of used questionnaires in the study and/or [48]; 6) Short follow-up [48]. Furthermore, the studies measuring adherence did not consider the effect of antidepressants or interaction between nurse and participant [38]. The educating nurse as confounding factor may be a moderator for self-efficacy, thus revealing a factor that may be used to improve self-efficacy in future interventions in a larger sample. Future studies need to include more explicit reporting of how self-efficacy and depression are operationalized in interventions.

The contradictory results about the effects of self-efficacy and depression on self-care predicted medication adherence $[34,48,50,55]$ in the current review may be explained by the fact that several studies used convenience sample, the method for data collection or duration of follow-up. Further, the use of self-reported questionnaires might not be the most reliable method to assess medication adherence for elderly patients, who may have a memory deficit or cognitive impairment [62]. Thus, the results may not always reflect the real situation.

According to self-efficacy theory of depression [23] the findings can be explained; failure to meet the goals of self-care may be influenced by low/lack of sufficient self-efficacy and/or depression. However, the reviewed literature also confirms that interventions aimed at improving self-efficacy can have positive effects on confidence and the ability to initiate and maintain self-care behavior [63]. Although only one study, we found that self-efficacy is a better predictor for medication and dietary adherence [50] than depression in HF patients. Hence, nurses may emphasize on to increase patient's self-efficacy level than to concentrate on depression to identify and enhance self-care. These results have important implications for clinical practice.

The results imply that interventions targeted to modify one of the independent variables may indirectly be effective in modifying the others. For example, interventions enhancing self-efficacy may lower levels of depression and also indirectly strengthen self-care. Furthermore, contextual factors that fall outside of traditional elements of an HF self-care program, such as social interaction [64], may be considered for encouraging self-care with optimal follow-up as well as to maintain established self-efficacy and avoid failures with depressive responses [15].

A specific issue that deserves further interrogation is the role of sexual self-efficacy as a factor in lowering depression. As only one of the studies dealt with sexual self-efficacy, it was not possible to draw any definite conclusions regarding the relationship between sexual self-efficacy and depression. This issue needs urgent further exploration, as sexual dysfunction has been reported in $60 \%-87 \%$ of the patients with HF [65]. Furthermore, reliance upon the BDI [50], which includes a number of symptoms (e.g., sexual incompetence and fatigue) common to both HF and depression, may have contributed to inaccuracies regarding the measurement of depression. A statement from the American Heart association explains how sexual counselling led to cardiac patients gaining better confidence in their ability to engage in sexual activity $[1,66]$. However, future research needs to address the relationship between sexual activity, self-efficacy and depression as a factor that may affect self-care in HF patients.

\section{Study Limitations}

Although this is the first review integrating self-efficacy and depression in HF patients in the self-care context, the findings and conclusion of the review should be considered within the context of its limitations. Only articles published in English were included, which might have resulted in exclusion of relevant studies published in other languages. It is worth noting that a wide range of research strategies were used, with a variety of settings for investigations. The majority of the studies were cross-sectional, i.e. only a snapshot, leading to difficulties in making a causal inference. Single-centered and small sample size studies decreases the ability to generalize the findings. Furthermore, the majority of the studies included both men and women, but did not report the research findings by gender.

Though standardized instruments were used, a susceptibility of errors is caused by respondents answering in accordance with their individual view concerning affective and behavioral dimensions of psychological variables like self-efficacy and depression. This may also be the issue even if the questionnaires been interviewed by healthcare 
professionals. As the review is based on original studies from different disciplines, the research methods, concepts, theories relating to a particular phenomenon may vary in different disciplines. Although integrative reviews have the potential to enhance a comprehensive and holistic understanding of the relationship between studied topics; combining diverse data sources is complex and challenging $[32,33]$. Besides, result interpretation in the original studies may vary as only few studies mentioned the use of theoretical frameworks. Inclusion of theories helps to define concepts, establish a proposed association or interpret the findings [67]. Finally, we are limited by the methodological choices and quality of research reporting of the included studies.

\section{Conclusion}

Self-efficacy and depression are both latent variables, and crucial for self-care in patients with HF; but scarcely described or investigated in the published literature. Because of diverse relationships described in the literature, the urgent need of filling the knowledge gap between self-efficacy and depression will be of great clinical importance for achieving better clinical outcome in patients with $\mathrm{HF}$ to minimize suffering and reduce the economic burden by promoting self-care.

\section{Clinical Implications}

An important implication of the analysis is that self-efficacy is influenced by depression, which is potentially modifiable. Nurses should therefore include components specifically geared towards increasing self-efficacy for selfcare and mood in their assessments. By taking note of signs of depression and efforts to build and reinforce self-efficacy, it may be possible to help HF patients with poor selfcare at an earlier stage. Findings from this review helps to better understand the role of self-efficacy and depression; and encourage nurses to develop particular interventions to promote self-care in HF patients. This also means that interventions should be implemented and measurements should be repeated in patients with HF. Routine visits should include anamnesis for early identification of motivational barriers and signs of depression. Many of the HF patients are older and live alone, so home-based interventions that foster social contact and interaction may be an effective strategy to sustain self-efficacy, reduce depression and encourage self-care behavior. However, reinforcing progress made at regular intervals is an effective way to improve self-confidence and continued motivation to selfcare in chronic conditions like HF. Finally, as a consequence this review contributes to integrating the notion of self-efficacy and depression into self-care, and the implications of this study should be considered in future guidelines.

\section{Highlights}

- Lower self-efficacy is related to more depressive symptoms and vice versa.

- Self-efficacy and depression affects self-care behav- ior in patients with heart failure.

- Depression is associated with lower self-efficacy.

- Boosting self-efficacy may be initial targeting point for better clinical outcome.

\section{Acknowledgement}

We would convey our gratitude to Celia Aijmer Rydsjö for the linguistic revision of the paper.

\section{Author Contribution}

Both authors have contributed to the literature search, data extraction and writing the manuscript.

\section{Funding}

This research received no specific grant from any funding agency in the public, commercial, or not for profit sectors.

\section{Conflict of Interest}

None.

\section{References}

1. McMurray JJ, Adamopoulos S, Anker SD, Auricchio A, Bohm M, et al. (2012) ESC Guidelines for the diagnosis and treatment of acute and chronic heart failure 2012: The task force for the diagnosis and treatment of acute and chronic heart failure 2012 of the European Society of Cardiology. Developed in collaboration with the Heart Failure Association (HFA) of the ESC. Eur Heart J 33: 1787-1847.

2. LÓPEZ-SENDÓN J (2011) The heart failure epidemic. Medicographia 33: 363-369.

3. Stewart S, Ekman I, Ekman T, Oden A, Rosengren A (2010) Population impact of heart failure and the most common forms of cancer: A study of 1162309 hospital cases in Sweden (1988 to 2004). Circ Cardiovasc Qual Outcomes 3: $573-580$.

4. Jhund PS, Macintyre K, Simpson CR, Lewsey JD, Stewart $S$, et al. (2009) Long-term trends in first hospitalization for heart failure and subsequent survival between 1986 and 2003: A population study of 5.1 million people. Circulation 119: 515-523.

5. Go AS, Mozaffarian D, Roger VL, Benjamin EJ, Berry JD, et al. (2014) Executive summary: Heart disease and stroke statistics-2014 update: A report from the American Heart Association. Circulation 129: 399-410.

6. Maggioni AP, Dahlstrom U, Filippatos G, Chioncel O, Crespo Leiro M, et al. (2013) EURObservational Research Programme: Regional differences and 1-year follow-up results of the Heart Failure Pilot Survey (ESC-HF Pilot). Eur J Heart Fail 15: 808-817.

7. Buck HG, Dickson VV, Fida R, Riegel B, D'Agostino F, et al. (2015) Predictors of hospitalization and quality of life in heart failure: A model of comorbidity, self-efficacy and selfcare. Int J Nurs Stud 52: 1714-1722.

8. Hu XL, Hu XY, Su YL, Qu MY, MA D (2015) The changes and factors associated with post-discharge self-care behaviors among Chinese patients with heart failure. Patient Prefer Adherence 9: 1593-1601.

9. Chen AM, Yehle KS, Albert NM, Ferraro KF, Mason HL, et al. (2014) Relationships between health literacy and heart 
failure knowledge, self-efficacy, and self-care adherence. Res Social Adm Pharm 10: 378-386.

10. Boyne JJ, Vrijhoef HJ, Spreeuwenberg M, De Weerd G, Kragten J, et al. (2014) Effects of tailored telemonitoring on heart failure patients' knowledge, self-care, self-efficacy and adherence: A randomized controlled trial. Eur J Cardiovasc Nurs 13: 243-252.

11. Riegel B, Dickson VV (2008) A situation-specific theory of heart failure self-care. J Cardiovasc Nurs 23: 190-196.

12. Riegel B, Vaughan Dickson V, Goldberg LR, Deatrick JA (2007) Factors associated with the development of expertise in heart failure self-care. Nurs Res 56: 235-243.

13. Bandura A (1977) Self-efficacy: Toward a unifying theory of behavioral change. Psychol Rev 84: 191-215.

14. Riegel B, Lee CS, Dickson VV, Medscape (2011) Self care in patients with chronic heart failure. Nat Rev Cardiol 8: 644-654.

15. Dekker RL (2014) Patient perspectives about depressive symptoms in heart failure: A review of the qualitative literature. J Cardiovasc Nurs 29: E9-E15.

16. Jiang W, Kuchibhatla M, Clary GL, Cuffe MS, Christopher EJ, et al. (2007) Relationship between depressive symptoms and long-term mortality in patients with heart failure. Am Heart J 154: 102-108.

17. Lainscak M, Blue L, Clark AL, Dahlstrom U, Dickstein K, et al. (2011) Self-care management of heart failure: Practical recommendations from the Patient Care Committee of the Heart Failure Association of the European Society of Cardiology. Eur J Heart Fail 13: 115-126.

18. Rutledge T, Reis VA, Linke SE, Greenberg BH, Mills PJ (2006) Depression in heart failure a meta-analytic review of prevalence, intervention effects, and associations with clinical outcomes. J Am Coll Cardiol 48: 1527-1537.

19. Paykel ES, Brugha T, Fryers T (2005) Size and burden of depressive disorders in Europe. Eur Neuropsychopharmacol 15: 411-423.

\section{0. http://www.who.int/topics/depression/en/}

21. Sokoreli I, de Vries JJ, Riistama JM, Pauws SC, Steyerberg EW, et al. (2016) Depression as an independent prognostic factor for all-cause mortality after a hospital admission for worsening heart failure. Int J Cardiol 220: 202-207.

22. Sarkar U, Ali S, Whooley MA (2009) Self-efficacy as a marker of cardiac function and predictor of heart failure hospitalization and mortality in patients with stable coronary heart disease: Findings from the Heart and Soul Study. Health Psychol 28: 166-173.

23. Maddux J, Meier LJ (1995) Self-efficacy and depression. In: Maddux JE, Self-Efficacy, Adaptation, and Adjustment: Theory, Research, and Application.

24. Bandura A (2010) Self-Efficacy. The Corsini Encyclopedia of Psychology. 1-3.

25. Locke EA, Latham GP (1990) A theory of goal setting \& task performance. Prentice-Hall, Englewood Cliffs, NJ.

26. Schwarzer R, Fuchs R (1996) Self-efficacy and health behaviours. Predicting Health Behaviour 163-196.

27. Katch $H$, Mead $H(2010)$ The role of self-efficacy in cardiovascular disease self-management: $A$ review of effective programs. Patient Intelligence 2: 33-44.

28. Riegel B, Dickson VV, Faulkner KM (2016) The situation-specific theory of heart failure self-care: Revised and updated. J Cardiovasc Nurs 31: 226-235.

29. Orem D (1995) Nursing: Concepts of practice. ( $5^{\text {th }}$ edn), Mosby, St. Louis.

30. Moser DK, Watkins JF (2008) Conceptualizing self-care in heart failure: A life course model of patient characteristics. J Cardiovasc Nurs 23: 205-218.

31. Holloway A, Watson HE (2002) Role of self-efficacy and behaviour change. Int J Nurs Pract 8: 106-115.

32. Torraco RJ (2005) Writing integrative literature reviews: Guidelines and examples. Human Resource Development Review 4: 356-367.

33. Whittemore R, Knafl K (2005) The integrative review: Updated methodology. J Adv Nurs 52: 546-553.

34. Aggarwal B, Pender A, Mosca L, Mochari-Greenberger H (2015) Factors associated with medication adherence among heart failure patients and their caregivers. J Nurs Educ Pract 5: 22-27.

35. Clark AP, McDougall G, Riegel B, Joiner-Rogers G, Innerarity S, et al. (2015) Health status and self-care outcomes after an education-support intervention for people with chronic heart failure. J Cardiovasc Nurs 30: S3-S13.

36. Duncan K, Pozehl B, Hertzog M, Norman JF (2014) Psychological responses and adherence to exercise in heart failure. Rehabil Nurs 39: 130-139.

37. Gary R (2006) Exercise self-efficacy in older women with diastolic heart failure: Results of a walking program and education intervention. J Gerontol Nurs 32: 31-39.

38. Gellis ZD, Kenaley BL, Ten Have T (2014) Integrated telehealth care for chronic illness and depression in geriatric home care patients: The Integrated Telehealth Education and Activation of Mood (I-TEAM) study. J Am Geriatr Soc 62: 889-895

39. Jerant A, Kravitz R, Moore-Hill M, Franks P (2008) Depressive symptoms moderated the effect of chronic illness self-management training on self-efficacy. Med Care 46: 523-531.

40. LaFramboise LM, Todero CM, Zimmerman L, Agrawal S (2003) Comparison of health buddy with traditional approaches to heart failure management. Fam Community Health 26: 275-288.

41. Maeda U, Shen BJ, Schwarz ER, Farrell KA, Mallon S (2013) Self-efficacy mediates the associations of social support and depression with treatment adherence in heart failure patients. Int J Behav Med 20: 88-96.

42. Paukert AL, LeMaire A, Cully JA (2009) Predictors of depressive symptoms in older veterans with heart failure. Aging Ment Health 13: 601-610.

43. Reschke AH (2001) Depression and functional impairment in outpatients with congestive heart failure. ProQuest Information \& Learning (US).

44. Rosland AM, Heisler M, Choi HJ, Silveira MJ, Piette JD (2010) Family influences on self-management among functionally independent adults with diabetes or heart failure: Do family members hinder as much as they help? Chronic IIIn 6: 22-33.

45. Steinke EE, Wright DW, Chung ML, Moser DK (2008) Sexual self-concept, anxiety, and self-efficacy predict sexual activity in heart failure and healthy elders. Heart Lung 37 : 323-333.

46. Tovar EG, Dekker RL, Chung ML, Gokun Y, Moser DK, et al. (2015) Self-efficacy mediates the relationship of depres- 
sive symptoms and social support with adherence in patients with heart failure. J Health Psychol.

47. Yeh GY, Wood MJ, Wayne PM, Quilty MT, Stevenson LW, et al. (2013) Tai chi in patients with heart failure with preserved ejection fraction. Congest Heart Fail 19: 77-84.

48. Xiong GL, Fiuzat M, Kuchibhatla M, Krishnan R, O'Connor CM, et al. (2012) Health status and depression remission in patients with chronic heart failure: Patient-reported outcomes from the SADHART-CHF trial. Circ Heart Fail 5: 688-692.

49. Morgan AL, Masoudi FA, Havranek EP, Jones PG, Peterson $P N$, et al. (2006) Difficulty taking medications, depression, and health status in heart failure patients. J Card Fail 12: 54-60.

50. Schweitzer RD, Head K, Dwyer JW (2007) Psychological factors and treatment adherence behavior in patients with chronic heart failure. J Cardiovasc Nurs 22: 76-83.

51. Schnell-Hoehn KN, Naimark BJ, Tate RB (2009) Determinants of self-care behaviors in community-dwelling patients with heart failure. J Cardiovasc Nurs 24: 40-47.

52. Fan X, Lv F (2014) Psychosocial factors associated with self-efficacy for managing chronic disease in patients with chronic heart failure. Eur J Cardiovasc Nurs 15: 255-261.

53. Peters-Klimm F, Kunz CU, Laux G, Szecsenyi J, MullerTasch T (2010) Patient- and provider-related determinants of generic and specific health-related quality of life of patients with chronic systolic heart failure in primary care: A cross-sectional study. Health Qual Life Outcomes 8: 98.

54. Joekes K, Van Elderen T, Schreurs K (2007) Self-efficacy and overprotection are related to quality of life, psychological well-being and self-management in cardiac patients. $J$ Health Psychol 12: 4-16.

55. Kenealy TW, Parsons MJ, Rouse AP, Doughty RN, Sheridan NF, et al. (2015) Telecare for diabetes, CHF or COPD: Effect on quality of life, hospital use and costs. A randomised controlled trial and qualitative evaluation. PLoS One 10: e0116188.

56. Rydlewska A, Krzysztofik J, Libergal J, Rybak A, Banasiak W, et al. (2013) Health locus of control and the sense of self-efficacy in patients with systolic heart failure: A pilot study. Patient Prefer Adherence 7: 337-343.

57. Tsay SL, Chao YF (2002) Effects of perceived self-efficacy and functional status on depression in patients with chronic heart failure. J Nurs Res 10: 271-278.

58. Luszczynska A, Gutiérrez-Doña B, Schwarzer R (2005) General self-efficacy in various domains of human functioning: Evidence from five countries. International Journal of Psychology 40: 80-89.

59. Do V, Young L, Barnason S, Tran H (2015) Relationships between activation level, knowledge, self-efficacy, and self-management behavior in heart failure patients discharged from rural hospitals. F1000Res 4: 150.

60. Spaling MA, Currie K, Strachan PH, Harkness K, Clark AM (2015) Improving support for heart failure patients: A systematic review to understand patients' perspectives on selfcare. J Adv Nurs 71: 2478-2489.

61. Maciejewski P, Prigerson H, Mazure C (2000) Self-efficacy as a mediator between stressful life events and depressive symptoms. Differences based on history of prior depression. Br J Psychiatry 176: 373-378.

62. Currie K, Rideout A, Lindsay G, Harkness K (2015) The association between mild cognitive impairment and self-care in adults with chronic heart failure: A systematic review and narrative synthesis. J Cardiovasc Nurs 30: 382-393.

63. Lee LL, Arthur A, Avis M (2008) Using self-efficacy theory to develop interventions that help older people overcome psychological barriers to physical activity: A discussion paper. Int J Nurs Stud 45: 1690-1699.

64. Davis KK, Himmelfarb CR, Szanton SL, Hayat MJ, Allen JK (2015) Predictors of heart failure self-care in patients who screened positive for mild cognitive impairment. J Cardiovasc Nurs 30: 152-160.

65. Jaarsma T (2017) Sexual function of patients with heart failure: Facts and numbers. ESC Heart Fail 4: 3-7.

66. Levine GN, Steinke EE, Bakaeen FG, Bozkurt B, Cheitlin MD, et al. (2012) Sexual activity and cardiovascular disease: A scientific statement from the American Heart Association. Circulation 125: 1058-1072.

67. Theory and Why It is Important. Social and Behavioral Theories. e-Source: Behavioral \& Sciences Research, National Institutes of Health. 